\title{
Construção e ensaio de pórticos com tirante em madeira laminada colada
}

\author{
Construction and testing of frames with glued laminated timber with tie-rod \\ Construcción y ensayo de pórticos con tirantes en madera laminada pegada
}

Recebido: 24/01/2022 | Revisado: 29/01/2022 | Aceito: 02/02/2022 | Publicado: 04/02/2022

\author{
Desirè Coraça Possa \\ ORCID: https://orcid.org/0000-0002-4115-348X \\ Universidade Estadual do Oeste do Paraná, Brasil \\ E-mail: desicpossa@gmail.com \\ Alfredo Petrauski \\ ORCID: https://orcid.org/0000-0002-3633-2600 \\ Universidade Estadual do Oeste do Paraná, Brasil \\ E-mail: petrausk@terra.com.br \\ Sandra Maria Ferreira Couri Petrauski \\ ORCID: https://orcid.org/0000-0002-4651-4184 \\ Universidade Estadual do Oeste do Paraná, Brasil \\ E-mail: sandra.petrauski@unioeste.br \\ Gustavo Savaris \\ ORCID: https://orcid.org/0000-0002-3311-2426 \\ Universidade Tecnológica Federal do Paraná, Brasil \\ E-mail: gsavaris@utfpr.edu.br \\ Rodrigo Aparecido Jordan \\ ORCID: https://orcid.org/0000-0002-2479-4461 \\ Universidade Federal da Grande Dourados, Brasil \\ E-mail: rodrigojordan@ufgd.edu.br \\ Ricardo Lessa Azevedo \\ ORCID: https://orcid.org/0000-0001-7218-2251 \\ Universidade Estadual do Oeste do Paraná, Brasil \\ E-mail: ricardo.1.azevedo@gmail.com \\ Débora Coraça Possa \\ ORCID: https://orcid.org/0000-0003-2172-0130 \\ Universidade Estadual do Oeste do Paraná, Brasil \\ E-mail: deboracpossa@gmail.com \\ Victor Hugo Lazzaretti Padilha \\ ORCID: https://orcid.org/0000-0002-3811-7007 \\ Universidade Estadual do Oeste do Paraná, Brasil \\ E-mail: victorhugolpadilha@gmail.com \\ Karina Taiza Tomé \\ ORCID: https://orcid.org/0000-0002-1044-820X \\ Universidade Estadual do Oeste do Paraná, Brasil \\ E-mail: karinataizatome@gmail.com \\ Mateus Couri Petrauski \\ ORCID: https://orcid.org/0000-0002-5017-1356 \\ Universidade Estadual do Oeste do Paraná, Brasil \\ E-mail: mateus.petrauski@gmail.com \\ Adolfo III Encheandia La Torre \\ ORCID: https://orcid.org/0000-0002-5251-4738 \\ Centro Universitário da Fundação Assis Gurgacz, Brasil \\ E-mail: adolfo3eng@gmail.com
}

\begin{abstract}
Resumo
A indústria da construção civil é uma grande consumidora de recursos naturais, gerando muitos resíduos e sendo responsável por grande parte dos impactos ambientais mundiais. $\mathrm{O}$ emprego da madeira em estruturas ressurge como um material ambientalmente correto no setor da construção civil e agrícola por ser um material construtivo/estrutural renovável e seu uso de forma permanente contribui com a redução das emissões de carbono na atmosfera. Com isso, o presente estudo objetivou executar e ensaiar pórticos com tirantes, feitos em madeira laminada colada, de modo a avaliar sua aplicação estrutural em aviários. Foram confeccionados quatro pórticos em escala reduzida com tirantes de barras rosqueadas de 3/8", com vão livre de 1,9 metros e altura de pilar de 1,83 metros. Os materiais utilizados para a confecção dos pórticos foram a madeira de Pinus sp. e adesivo bicomponente à base de óleos vegetais. As estruturas romperam para uma carga média de 1,37 vezes a carga de verificação estabelecida e exibiram deslocamentos próximos a linearidade mesmo para cargas elevadas. Ainda, obteve-se um coeficiente de correlação de 0,95 entre a densidade aparente da madeira dos pórticos com sua resistência. Desta forma, as evidências obtidas indicam que o emprego do tirante nas estruturas promoveu a melhoria do desempenho mecânico quanto à resistência e rigidez.
\end{abstract}

Palavras-chave: Estruturas de madeira; Madeira laminada colada; Adesivo. 


\begin{abstract}
The civil construction industry consumes a large amount of natural resources, generating a lot of waste and being responsible for a considerable part of worldwide environmental impacts. The use of timber in structures in civil and agricultural construction resurfaces as a more acceptable solution considering it's a renewable material for structures and other building parts. Furthermore, the use of wood in a permanent form contributes with the reduction of carbon emissions in the atmosphere, the objective of the present study was a manufacture and test glulam frames with steel cables to evaluate its application as a structural member in poultry farm building. Four reduced scale glulam frames with 1.9 m spam, $1.83 \mathrm{~m}$ column and a 3/8" diameter threaded steel bar as a cable under tension were manufactured. The material used in the frames were wood from the species Pinus sp, and a two-component adhesive based on vegetables oils. The mean ultimate load of the testes frames was about 1.37 times the design load. Furthermore, the displacement development observer in the tests was approximately linear even the loads were high. The value obtained for the Pearson correlation coefficient between the apparent wood density and the frame's strehngth was 0.95. Finally, the results of the study indicate that the use of a steel cable in the frames improved the mechanical behavior regarding structural strength and stiffness.
\end{abstract}

Keywords: Wood structures; Glued laminated timber; Adhesives.

\begin{abstract}
Resumen
La industria de la construcción civil es una grande consumidora de recursos naturales, generando así muchos residuos y siendo responsable por grande parte de los impactos ambientales mundiales. El empleo de la madera en estructuras se muestra como un material ambientalmente correcto en el sector de la construcción civil y agrícola por ser un material constructivo/estructural renovable y su uso de forma permanente contribuye con la reducción de las emisiones de carbono en la atmósfera. Con eso, el presente estudio objetiva ejecutar y ensayar pórticos con tirantes, hechos en madera laminada pegada, a manera de poder calificar su aplicación estructural en aviarios. Fueron confeccionados cuatro pórticos en escala reducida con tirantes de barras de metal con rosca de 3/8", con distancia horizontal libre de 1,9 metros y altura del pilar con 1,83 metros. Los materiales utilizados para la fabricación de los pórticos fueron la madera de Pinus sp. y pegamiento bicomponente con base de aceites vegetales. Las estructuras rompieron para una carga media de 1,37 veces la carga de verificación establecida y mostraron deslocalización próximos a la linearidad mismo con cargas elevadas. Por así, se obtuvo un coeficiente de correlación de 0,95 entre la densidad aparente de la madera de los pórticos con su resistencia. De esta forma, las evidencias obtenidas indican que el empleo de tirantes en la estructura demuestra la mejoría del desempeño mecánico relacionado con la resistencia y rigidez.
\end{abstract}

Palabras clave: Estructuras em madera; Madera laminada pegada; Pegamiento.

\title{
1. Introdução
}

A consciência ambiental e o consumo sustentável são fatores que vêm conquistando espaço na sociedade a cada ano. Assim, surge a necessidade de pesquisas nos mais diversos setores acerca da sustentabilidade dos produtos, desde a sua obtenção até o seu uso final, visando o emprego de matérias-primas renováveis e que provoquem menor impacto ao meio ambiente (Tambosi et al., 2014; Arquinto et al., 2016; Martens et al., 2016).

Nesse contexto, a indústria da construção civil é uma das principais consumidoras de recursos naturais e geradoras de resíduos, sendo responsável por grande parte dos impactos ambientais mundiais (Green \& Taggart, 2017). Segundo a Fundação Dom Cabral (2013), o setor consome $75 \%$ de todos os recursos naturais, $44 \%$ da energia produzida no país e responde por cerca de $40 \%$ de todo o resíduo gerado pela atividade humana. Isto é agravado pelo fato de que a maior parte dos insumos utilizados não são provenientes de fontes renováveis.

Tais efeitos ambientais podem ser reduzidos com a adoção de medidas que considerem o verdadeiro impacto de cada material (Azevedo et al., 2020). Assim, a madeira volta a ser lembrada como um material ambientalmente correto em diversos âmbitos industriais, inclusive na construção civil e agrícola, visto que, além de ser o único material construtivo/estrutural renovável, o uso da madeira de forma permanente reduz as emissões de carbono na atmosfera, devido à fixação de carbono (Hafner et al., 2013; Bissoli-Dalvi et al., 2017; Maiti et al., 2020).

Pensando desde a extração até o seu emprego final, a madeira gera menos resíduos sólidos, produz menos gases do efeito estufa, requer menos energia para o seu beneficiamento e apresenta menor poluição da água e do ar, quando comparada com o aço e o concreto (CWC, 2002). Além do impacto ambiental positivo, a utilização da madeira na construção civil promove o crescimento do setor madeireiro, principalmente de florestas plantadas, contribuindo na preservação de florestas 
nativas (Gandini et al., 2017).

Embora a madeira seja um excelente material estrutural, sua utilização ainda sofre muito preconceito no Brasil, principalmente pela falta de conhecimento específico a seu respeito. Já em países da Europa e América do Norte, a cultura da madeira para fins estruturais é mais difundida, e detém-se amplo domínio em técnicas construtivas com o material (Pfeil \& Pfeil, 2003; Marquardt et al., 2018).

Uma das técnicas utilizadas nesses países é a Madeira Laminada Colada (MLC) que possibilita a execução de peças com maiores dimensões e em diversas geometrias, com potencial para resolver as limitações geométricas impostas pela madeira serrada de reflorestamento, sendo recomendada para qualquer tipologia construtiva.

Estudos recentes sobre a utilização da técnica de madeira laminada colada em pórticos estruturais foram feitos por autores como Couri Petrauski et al. (2016), Stringari et al. (2020) e Filippini (2020). Embora tais pesquisas tenham obtido resultados satisfatórios quanto ao seu desempenho, ainda há espaço para o estudo e desenvolvimento de outras soluções estruturais, bem como variações dos estudos desenvolvidos, na procura de outras opções seguras e econômicas.

Tratando-se de pórticos estruturais para emprego em aviários de postura, Stringari et al. (2020) e Filippini (2020) ensaiaram pórticos considerando o uso da telha de aluzinco que proporciona maior economia, mas apresenta baixo conforto térmico para as aves. Neste sentido passa a ser interessante analisar o comportamento da estrutura utilizando uma telha que proporcione maior bem-estar aos animais confinados na instalação. Com isso, o presente estudo objetivou confeccionar e ensaiar pórticos triarticulados atirantados previstos para uso de cobertura em telha cerâmica, visando avaliar o comportamento estrutural das unidades executadas.

\section{Metodologia}

A parte experimental do trabalho foi realizada nas dependências do Laboratório de Estruturas e Materiais de Engenharia - LEME e do Laboratório de Tecnologia e Estruturas de Madeira - LATEM da Universidade Estadual do Oeste do Paraná - UNIOESTE, no Campus de Cascavel-PR.

Os principais materiais utilizados neste estudo foram a madeira de Pinus sp. e o adesivo bi componente à base de óleos vegetais. O adesivo foi adquirido na empresa KEHL® Indústria e Comércio, e é fornecido em dois componentes: o poliol e o isocianato. A madeira, por sua vez, proveniente de reflorestamento, foi obtida de árvores com 16 anos de idade.

A madeira foi caracterizada conforme a NBR 7190 (ABNT, 1997) para obter suas propriedades mecânicas, tais como: resistência à compressão paralela às fibras $\left(f_{c 0}\right)$, módulo de elasticidade na compressão paralela às fibras $\left(E_{c 0}\right)$, resistência ao cisalhamento paralelo às fibras $\left(f_{V 0}\right)$, resistência à tração na flexão ( $\left.f_{\text {fMo }}\right)$ e módulo de elasticidade à flexão $\left({ }_{M M 0}\right)$.

Para se obter as propriedades de desempenho de ligações coladas do adesivo com a madeira foram realizados ensaios para determinar a resistência ao cisalhamento na compressão de juntas coladas com as fibras paralelas e perpendiculares entre si $\left(f_{V v 0}, f_{V=90}\right)$, normatizado em parte pela ASTM D 905 (2013) e a resistência ao cisalhamento na torção de juntas coladas com as fibras paralelas e perpendiculares entre si $\left(f_{\mathrm{Vto}}, f_{\mathrm{Vt} 90}\right)$, utilizando a metodologia proposta por Petrauski et al. (2020).

\subsection{Pórtico com tirante}

Para a execução do pórtico com tirante foi adotada uma geometria, em escala reduzida, similar a utilizada por Stringari et al. (2020). A diferença entre este projeto e o dos autores foi a previsão da utilização de uma cobertura em telha cerâmica. Neste sentido, justifica-se a utilização do tirante dada a massa significativamente maior que o emprego da telha cerâmica impõe à estrutura.

Adotou-se o ângulo de inclinação de aproximadamente $23^{\circ}$ no plano da cobertura, inclusos beirais. A Figura 1 ilustra 
a configuração geométrica adotada bem como destaca a solução, em madeira laminada colada, para as seções principais do pórtico executado.

Figura 1 - Configuração geral do pórtico, dimensões em centímetros.
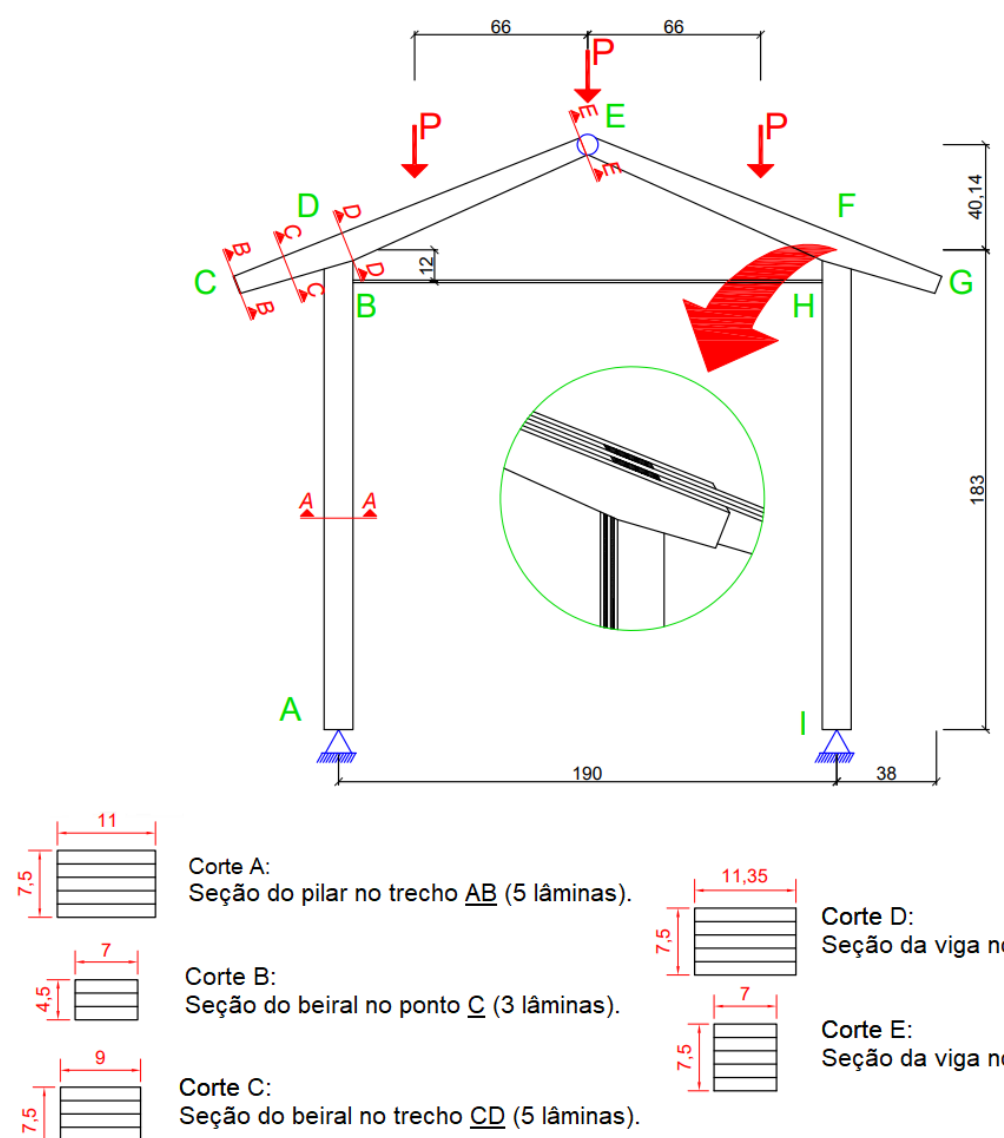

Corte D:

Seção da viga no trecho $\underline{\mathrm{DE}}$ (5 lâminas).

Corte E:

Seção da viga no ponto $\underline{E}$ (5 lâminas).

Fonte: Autores (2022).

Visando uma estrutura segura e ao mesmo tempo econômica, em regiões de menor solicitação estrutural, foi reduzida a inércia da barra de cobertura ao longo do seu comprimento, o que foi feito de forma linear.

A escolha das seções transversais principais, conforme indicadas na Figura 1, considerou inicialmente as seguintes decisões quanto à concepção: todas as lâminas utilizadas teriam espessura de $1,5 \mathrm{~cm}$ e, ainda, as seções dos pilares (barras $\mathrm{AD}$ e IF) e cobertura (barras CE e EG) teriam cinco lâminas coladas. Tais opções são as mesmas adotadas por Stringari et al. (2020) e Filippini (2020) em seus trabalhos. As cinco lâminas coladas impuseram, à exceção do beiral, uma espessura constante ao pórtico, equivalente a 7,5 cm. A utilização de 5 lâminas viabiliza também a execução das ligações rígidas, nos nós D e V. Nestes nós, duas lâminas do pilar e três lâminas da barra de cobertura se alternam na ligação permitindo 4 planos colados resistentes.

As alturas finais das barras indicadas na Figura 1 são tais que, para os valores médios de resistência da madeira, satisfazem as verificações estruturais estabelecidas na NBR 7190 (ABNT, 1997), para uma força total de 46,5 kN aplicada no pórtico (15,5 kN em cada um dos três pontos de aplicação de forças).

De modo geral as principais verificações para a madeira compreenderam: a estabilidade do pilar à flexo-compressão; a resistência das lâminas na região da ligação pilar-viga; a resistência ao cisalhamento; a resistência da barra de cobertura à flexo-compressão ou flexo-tração e os deslocamentos teóricos apresentados. Os diagramas de esforço cortante, momento fletor, esforço normal e as estimativas de deslocamentos foram obtidos com auxílio do programa Ftool, da PUC-Rio 
(https://www.ftool.com.br/Ftool/, 2017). Para o nível referencial de força total aplicada igual a 46,5 kN a estrutura estaria no limite de sua resistência, podendo manifestar ruptura.

Adicionalmente verificou-se a ligação colada entre a viga e o pilar, adotando-se o critério estabelecido por Couri Petrauski (1999) e Petrauski (2000). Destaque-se que o critério proposto realiza simultaneamente a verificação das tensões de cisalhamento provocadas pelas forças cortantes e normais e, também, aquelas advindas do momento fletor. Nesta técnica, o momento fletor atua como momento de torção em relação aos planos colados. Para condução desta verificação foram adotados os valores médios da caracterização da resistência das juntas conforme ilustrado na Tabela 1. Destaque-se que para a carga total referencial de 46,5 kN, a ligação também apresentava situação limite de desempenho.

Na porção de extremidade dos beirais utilizou-se três lâminas resistentes, como indicado na Figura 1. Contudo, nas seções dos beirais próximas aos nós $\mathrm{D}$ e $\mathrm{F}$ foram adotadas 5 lâminas. Isto foi feito por meio do prolongamento do comprimento das lâminas externas da viga no sentido do beiral, em aproximadamente $13 \mathrm{~cm}$. Mesmo procedimento já havia sido adotado por Filippini (2020) objetivando evitar-se fratura, na região da ligação, motivada por tração perpendicular às fibras causada pelo momento fletor atuante no local.

Devido ao fato de a ligação pilar-viga ser um ponto crítico da estrutura e ser necessário perfurar a seção para "fixar" o tirante de forma adequada, considerou-se não ser viável fazer uso do tirante no centro da ligação. Assim, o tirante foi colocado $12 \mathrm{~cm}$ abaixo do centro teórico da ligação.

Utilizou-se para execução do tirante barras comerciais rosqueadas de $3 / 8$ " de diâmetro. Tais barras rosqueadas facilitariam a protensão, garantindo o funcionamento pretendido. As barras rosqueadas foram adquiridas em comércio local com comprimento total de três metros. Realizou-se um ensaio de tração em máquina universal de ensaios e as barras exibiram uma resistência média de 30,6 kN. Destaque-se que, para o carregamento máximo referencial de 46,5 kN nos pórticos, o tirante estaria sujeito a $23,76 \mathrm{kN}$ de tração, o que foi considerado adequado uma vez que não se desejava ruptura destes elementos.

\subsection{Execução dos pórticos}

Foram confeccionados quatro pórticos com diferentes classes de densidade da madeira, considerada a variabilidade da densidade aparente do lote adquirido. O pórtico P1 foi confeccionado com madeira de densidade alta, o pórtico P2 com densidade média alta, o pórtico P3 com densidade média baixa e o pórtico P4 com densidade baixa. Cada pórtico foi executado em duas partes, sendo unidas, posteriormente, utilizando-se de um pino metálico no nó $\mathrm{E}$.

Primeiramente, as peças passaram por um processamento inicial, com a utilização da plaina desengrossadeira, desempenadeira e serra circular, para obter-se lâminas com dimensões próximas às estabelecidas no projeto.

No processamento final, realizado no dia da colagem, as lâminas foram processadas na plaina desengrossadeira e serradas na serra circular para se obter as dimensões finais e ângulos estabelecidos em projeto. Após, as lâminas foram limpas, com o auxílio de ar comprimido e escova, para eliminar sujeiras e acúmulos de pó, visando um bom resultado na colagem. A cada colagem era realizada uma montagem preliminar, sem adesivo, para conferir todas as peças e encaixes.

A quantidade de adesivo necessária para a colagem foi mensurada e separada em quatro recipientes, sendo um para cada plano colado. $\mathrm{O}$ adesivo foi aplicado em uma das faces e espalhado com uso de um pincel. Utilizou-se o adesivo na proporção em massa de 1:1,5 de isocianato e poliol, com consumo equivalente a $300 \mathrm{~g} / \mathrm{m}^{2}$. Realizou-se a colagem em tempo inferior à 10 minutos devido a rápida alteração da viscosidade do adesivo utilizado.

Após a colagem, as peças recebiam uma pressão de $0,8 \mathrm{MPa}$ controlada por meio de torquímetro eletrônico, o qual foi calibrado em todos os dias de colagem. O processo desde o início da colagem até a aplicação da pressão foi realizado em tempo médio de 42 minutos. 
Aferiu-se a pressão passado um período de 30 minutos e, por fim, as peças ficavam na prensa por um tempo mínimo de 12 horas. Passado este período, a estrutura era retirada e armazenada por um período mínimo de dez dias antes do ensaio. Considerados todos os dias de colagem a madeira apresentou teor de umidade médio igual a 12,26\%, em base seca.

\subsection{Ensaio dos pórticos}

Os pórticos foram ensaiados individualmente utilizando-se um quadro de reação em concreto armado disponível no LEME, conforme é possível visualizar na Figura 2 (a). Foram necessários alguns aparatos para a realização do ensaio, tais como: o sistema de aplicação de forças; o sistema de leitura de forças aplicadas; o sistema de contraventamento; os aparelhos de apoio dos pórticos e o sistema de leitura dos deslocamentos das estruturas. Isto é ilustrado na Figura 2 (b)

Figura 2 - (a) Quadro de reações com a estrutura e os aparatos e (b) disposição dos aparatos.
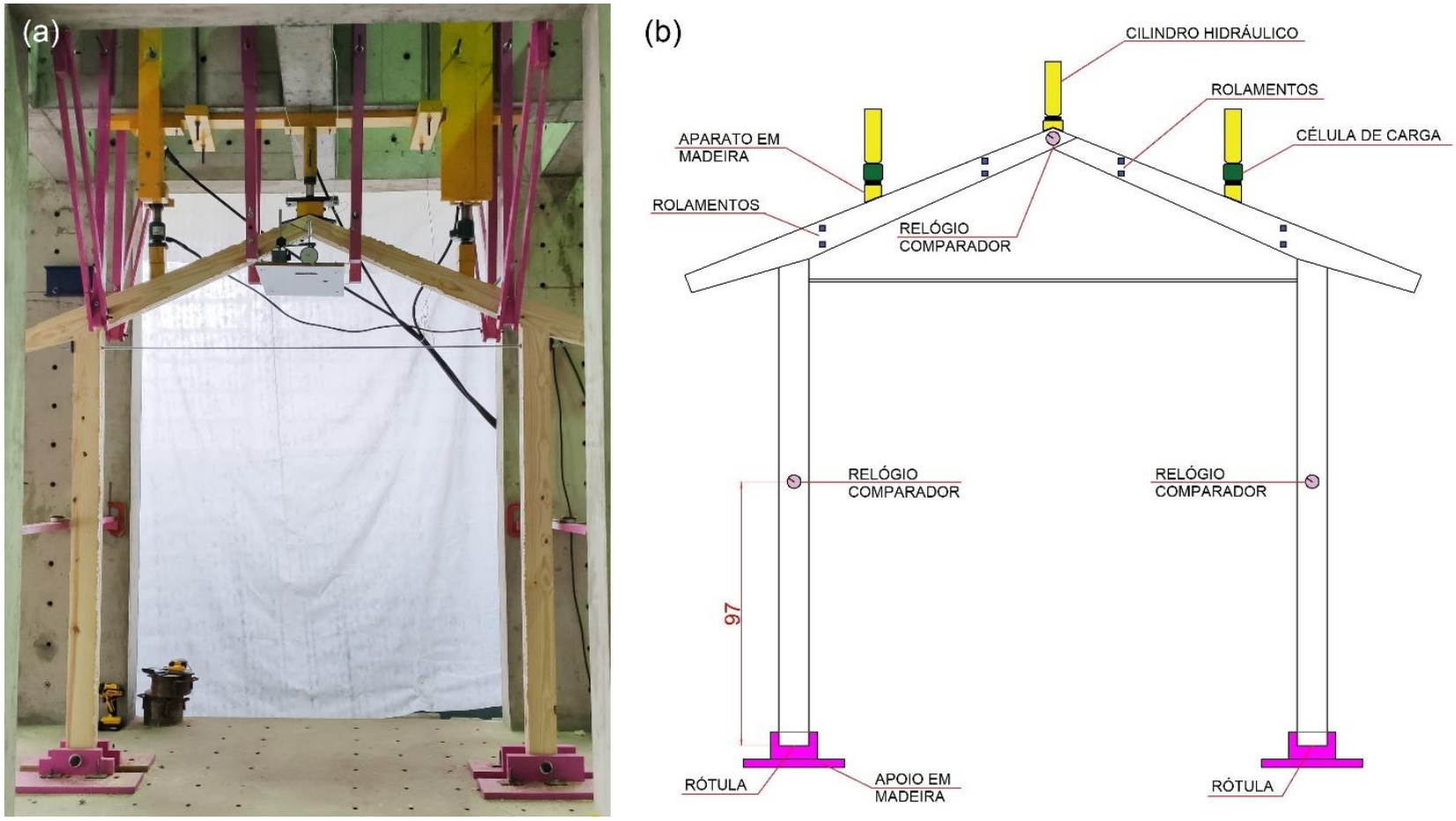

Fonte: Autores (2022).

O sistema de aplicação de forças foi composto por três cilindros hidráulicos que eram fixados no quadro de reação e alimentados por bomba hidráulica. Para aquisição das forças aplicadas, instalou-se duas células de carga associadas aos cilindros laterais. Para o contraventamento utilizou-se um conjunto de rolamentos metálicos localizados em diferentes pontos da viga de cobertura. Para o apoio dos pórticos foram utilizados aparatos que funcionaram como apoios de segundo gênero. A leitura dos deslocamentos do pórtico foi realizada por meio de três relógios comparadores, com resolução de 0,01 mm.

Após a instalação de todos os aparatos era iniciado cada ensaio. Primeiramente aplicava-se, duas vezes, uma força para a "acomodação" da estrutura de aproximadamente $3 \mathrm{kN}$ e realizava-se o tensionamento do tirante. Após o descarregamento da força de acomodação os relógios comparadores eram "zerados". Então, o ensaio era conduzido conforme as seguintes etapas:

I. Aplicação de força total aproximada de $12 \mathrm{kN}$ (4 kN por cilindro), com registro dos deslocamentos apresentados nos relógios comparadores para acréscimos regulares de carga de aproximadamente $3 \mathrm{kN}$ e, após, descarregamento da carga;

II. Repetição da etapa I; 
III. Aplicação de forças, com registro dos deslocamentos até aproximadamente $33 \mathrm{kN}$, seguida da retirada dos relógios e condução do carregamento até a ruptura da estrutura.

\section{Resultados}

Na Tabela 1 são apresentados os resultados da caracterização mecânica da madeira de Pinus sp. e os resultados da resistência ao cisalhamento por compressão e por torção das juntas coladas de Pinus sp.

Tabela 1 - Resultados da caracterização mecânica do Pinus sp. e da resistência ao cisalhamento na compressão e na torção de juntas coladas a $12 \%$ de umidade.

\begin{tabular}{ccccc}
\cline { 2 - 5 } & $\begin{array}{c}\mathrm{N}^{\circ} \text { de corpos de } \\
\text { prova }\end{array}$ & $\begin{array}{c}\text { Valores médios } \\
(\mathrm{MPa})\end{array}$ & $\begin{array}{c}\text { Valores característicos } \\
(\mathrm{MPa})\end{array}$ & $\begin{array}{c}\text { Coeficiente de variação } \\
(\%)\end{array}$ \\
\hline$f_{c 0}$ & 16 & 45,54 & 38,46 & 19,79 \\
$E_{E 0}$ & 16 & 12709 & - & 19,54 \\
$f_{V 0}$ & 39 & 11,48 & 8,12 & 21,89 \\
$f_{\text {tMo }}$ & 7 & 78,2 & 56,96 & 28,94 \\
$E_{\text {Mo }}$ & 7 & 11358 & - & 39,43 \\
$f_{V E 0}$ & 32 & 10,3 & 7,78 & 14,84 \\
$f_{V E 90}$ & 26 & 4,09 & 2,64 & 34,23 \\
$f_{V t 0}$ & 31 & 8,47 & 6,55 & 21,12 \\
$f_{V t 90}$ & 23 & 5,54 & 4,09 & 30,54 \\
\hline
\end{tabular}

Fonte: Autores (2022).

\subsection{Resistência apresentada pelas estruturas}

Os quatro pórticos foram ensaiados até a ruptura para analisar seu comportamento e a sua resistência. Na Tabela 2 são apresentadas informações acerca da resistência de cada pórtico, bem como sua massa, densidade aparente média e locais de ruptura.

Tabela 2 - Valores de resistência das estruturas e valores de deslocamentos médios para a carga de $12 \mathrm{kN}$, em milímetros.

\begin{tabular}{ccccccc}
\hline & & & & & \multicolumn{2}{c}{ Deslocamentos (mm) } \\
\cline { 5 - 7 } Pórtico & Massa sem & Densidade média & Local de \\
tirante $(\mathrm{kg})$ & Carente $\left(\mathrm{g} / \mathrm{cm}^{3}\right)$ & Ruptura & $\begin{array}{c}\text { Carga de Ruptura } \\
(\mathrm{kN})\end{array}$ & $\begin{array}{c}\text { Relógio 1 } \\
\text { (cumeeira) }\end{array}$ & $\begin{array}{c}\text { Relógios 2 e 3 } \\
\text { (pilares) }\end{array}$ \\
\hline P1 & 32,2 & 0,62 & Nó D e F & 71,47 & 3,69 & 1,08 \\
P2 & 27,4 & 0,53 & Nó D e F & 67,62 & 3,18 & 0,86 \\
P3 & 25,2 & 0,49 & Nó F & 60,19 & 2,92 & 0,97 \\
P4 & 23,1 & 0,45 & Nó D e F & 55,02 & 3,89 & 1,21 \\
\hline Média & 26,98 & 0,52 & - & 63,58 & 3,42 & 1,03 \\
\hline
\end{tabular}

Fonte: Autores (2022).

Todas as estruturas apresentaram ruptura na região externa da ligação rígida (nós D ou F), associada à tração e promovida provavelmente pelo elevado momento fletor atuante. As ocorrências indicaram falha por tração paralela às fibras nas duas lâminas do pilar que avançam na região da ligação para solidarizarem-se às três lâminas da barra de cobertura. Ainda, o pórtico P3 exibiu ruptura de uma das lâminas da cumeeira (Nó E), mas esta ocorrência não pareceu ser a responsável pela ruína da estrutura. Tal fratura pode ter ocorrido durante a liberação brusca da energia acumulada, no momento da ruína. 
Embora a ruína fosse esperada para uma carga total próxima de $46,5 \mathrm{kN}$, a ruptura das unidades experimentais só ocorreu para uma carga mínima de 55,02 kN. A média observada para os 4 exemplares foi de $63,6 \mathrm{kN}$, ou seja, 37\% superior à estimativa teórica. Ainda, por conta da elevada carga a qual estavam submetidas as estruturas, acredita-se que a face interna da ligação rígida já poderia ter manifestado esmagamento à compressão, antes da ruptura à tração. Contudo, devido ao excesso de adesivo, extravasado e não limpo, presente nesta região, a verificação de rompimentos à compressão foi comprometida. Nas Figuras 3 (a) e 3 (b), pode-se observar a ruptura em duas unidades, evidenciando a rotação da ligação quando ocorreu a ruptura.

Figura 3 - (a) Exemplo de ruptura no nó D e (b) exemplo de ruptura no nó F.

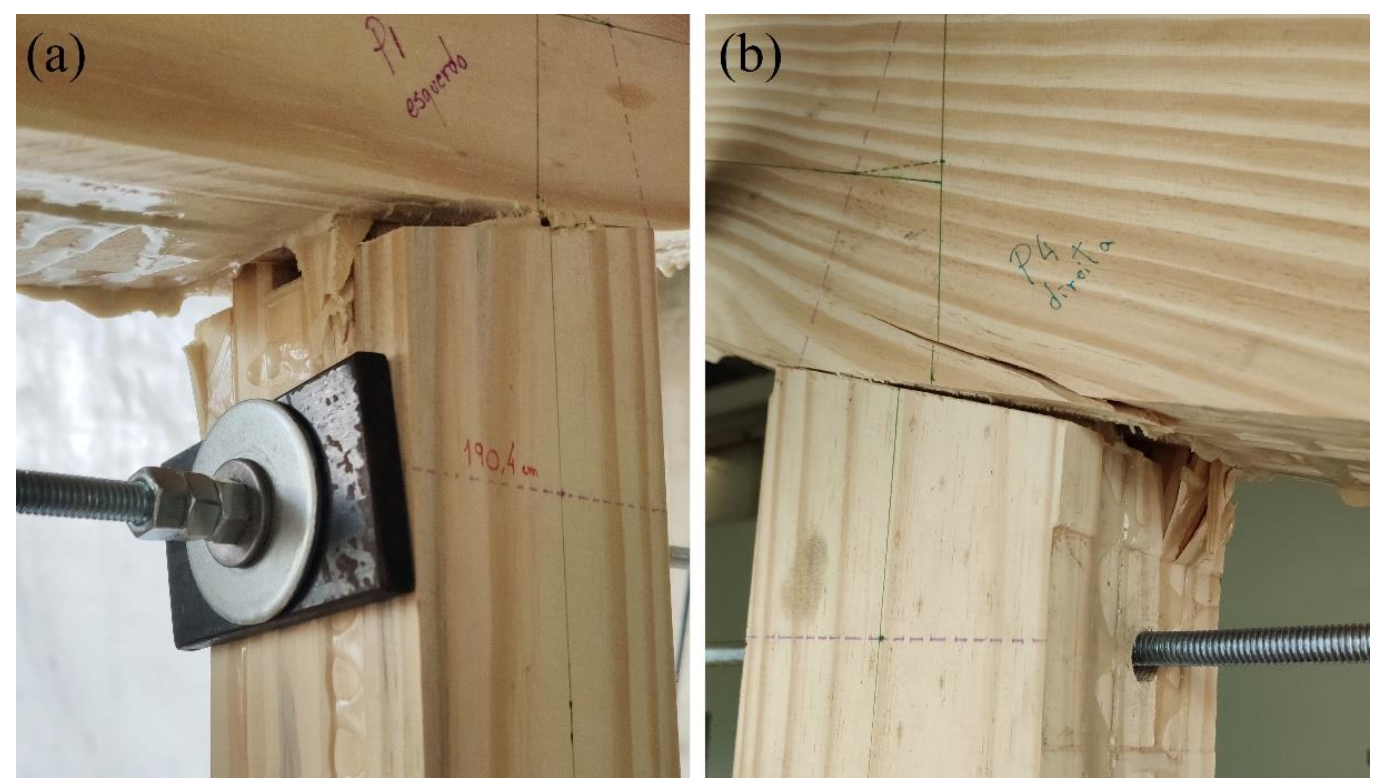

Fonte: Autores (2022).

Conforme apresentado na Tabela 2, também houve forte correlação entre a densidade aparente das unidades experimentais e sua carga de ruptura. O coeficiente de correlação encontrado foi da ordem de 0,95 .

\subsection{Rigidez apresentada pelas estruturas}

Os deslocamentos exibidos pelos relógios comparadores são apresentados na Tabela 2, e os valores correspondem às leituras médias feitas para o carregamento total de $12 \mathrm{kN}$ o que equivale a, aproximadamente, $25 \%$ da força total de referência de resistência teórica. Para este valor pode-se apresentar a média de três leituras consecutivas de cada estrutura haja vista a marcha experimental adotada e indicada na seção 2.3 deste trabalho. Este valor, ainda, seria muito próximo do valor de referência da carga de serviço dos pórticos caso se optasse por aplicar a minoração das resistências e majoração das ações, conforme critérios de projeto da NBR 7190 (ABNT, 1997). Apresenta-se, também, as médias dos valores de leitura dos relógios 2 e 3, localizados nos pilares, por corresponderem à mesma posição para cada lado simétrico da estrutura. Estes relógios foram instalados na porção intermediária da altura de cada pilar.

Os diagramas forças $\mathrm{x}$ deslocamentos para o relógio 1 da cumeeira e para os relógios 2 e 3 referentes aos pilares são apresentados na Figura 4. Considerados todos os valores obtidos, para todos os níveis de forças aplicadas nas quatro estruturas testadas, a equação de regressão linear, para deslocamentos da cumeeira, apresentou coeficiente $\mathrm{R}^{2}$ igual a 0,98 , o que indica boa adequação ao regime elástico, especialmente nos níveis de forças iniciais.

Figura 4 - a) Diagrama forças $x$ deslocamentos apresentado na cumeeira e b) nos pilares. 

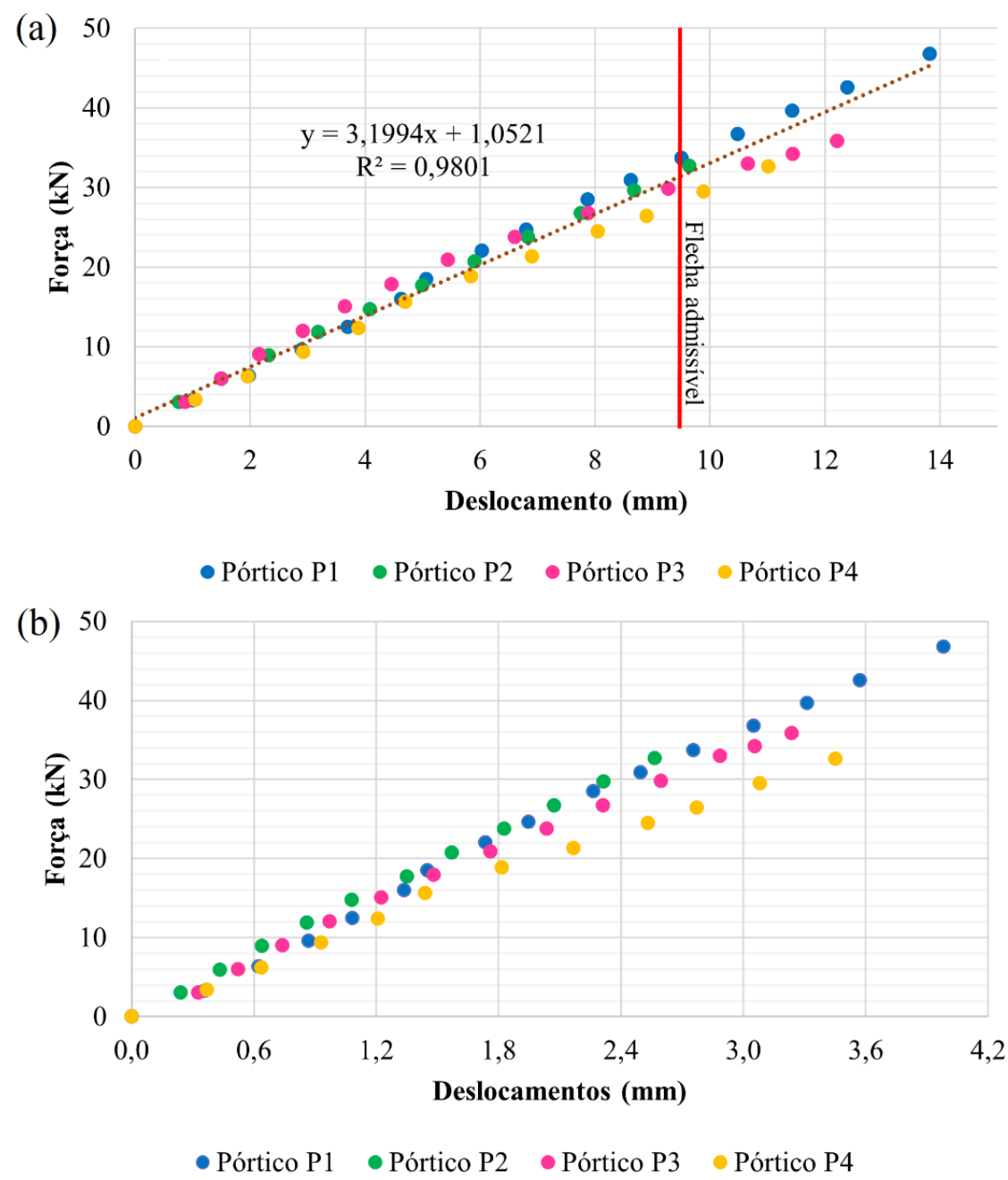

Fonte: Autores (2022).

Segundo a NBR 7190 (ABNT, 1997), a flecha máxima admissível para este tipo de estrutura não deve ser maior que L/200, sendo L o vão livre da estrutura. Tal situação é compatível com edificações agrícolas, como no caso desta pesquisa. Assim, para este estudo, a flecha máxima admissível foi de 9,5 mm. Como indica a Figura 4 (a) nota-se que, na cumeeira, as estruturas só atingiram tal deslocamento com carregamentos acima de $30 \mathrm{kN}$.

\section{Discussão}

Em relação à resistência de juntas coladas ao cisalhamento na compressão e na torção, Petrauski et al. (2020) encontraram, para juntas coladas paralelamente $\left(f_{V 0}\right)$ e perpendicularmente ( $\left.f_{V 90}\right)$ às fibras, a mesma tendência observada nesta pesquisa. Nestes trabalhos, independentemente do ensaio (compressão ou torção), as menores resistências ocorrem quando a colagem se dá com lâminas perpendiculares entre si. Ainda, entre as quatro respostas, o melhor e o pior desempenho foram encontrados no ensaio de compressão. Juntas coladas paralelas foram as mais resistentes e aquelas coladas perpendiculares entre si foram as de pior desempenho.

Nos trabalhos realizados por Couri Petrauski et al. (2016), Stringari et al. (2020) e Filippini (2020) os pórticos também romperam nas ligações rígidas (nós D ou F). Tal ocorrência parece ser esperada uma vez que, neste tipo de estrutura, a região da ligação é a mais solicitada por momento fletor e no dimensionamento e/ou verificações tende a ficar sujeita a condições limites. Nesta pesquisa, inclusive, as verificações realizadas já indicavam situação limite de resistência para as duas lâminas dos pilares que se ligavam àquelas da viga de cobertura. Contudo, conforme conclui Filippini (2020) pode-se melhorar 
o desempenho resistente destas ligações com a utilização de lâminas adicionais nesta região crítica, sem acréscimo significativo de materiais.

Couri Petrauski et al. (2016) e Stringari et al. (2020), ainda, observaram, em algumas lâminas, na região da ligação, rupturas por tração perpendicular às fibras, relacionadas provavelmente ao elevado momento fletor. Filippini (2020), ao contrário, conseguiu eliminar esta ocorrência nas lâminas externas utilizando-se de um prolongamento destas lâminas para além da região da ligação, no sentido do beiral. Nesta pesquisa adotou-se o mesmo procedimento da autora. Desta forma, também conseguiu-se evitar ruptura por tração perpendicular às fibras, naquela região.

Ao contrário das estruturas ensaiadas por Stringari et al. (2020) e Filippini (2020), os pórticos não manifestaram rompimento brusco na cumeeira (nó E). Pode-se justificar tal diferença por conta da utilização do tirante, que diminui consideravelmente o deslocamento naquela região.

A utilização do tirante para reduzir os esforços atuantes na ligação rígida teve um reflexo positivo na resistência das estruturas. Apesar deste estudo não ter utilizado as configurações geométricas idênticas dos estudos feitos por Stringari et al. (2020) e Filippini (2020), por se tratar de pórticos muito similares, comparou-se as suas de resistências. Os pórticos com uso de tirante apresentaram um aumento de resistência de $121 \%$ em comparação aos pórticos de Stringari et al. e de $67 \% \mathrm{em}$ comparação aos pórticos com reforço de Filippini. A média de ruptura dos pórticos de Strigari et al. foram de $28,79 \mathrm{kN}$ e os de Filippini foram de $38,02 \mathrm{kN}$, enquanto que neste trabalho a média foi de $63,58 \mathrm{kN}$.

Outro fator importante que pode ser analisado é que os pórticos confeccionados com madeira de maior densidade apresentaram uma maior resistência comparando-se aos de menor densidade. Esta é uma evidência relevante de que a densidade, relacionando-se positivamente com a resistência, irá afetar o desempenho de estruturas. Stringari et al. (2020) apresentam dados que permitem afirmar que, naquela pesquisa, o coeficiente de correlação entre a densidade da madeira das unidades experimentais e suas resistências foi de 0,82 . Neste caso a correlação apontou valor igual a 0,95 . Como consequência, fica a evidência da importância da seleção da madeira por meio da densidade, ação que pode ser realizada, especialmente em ambientes de produção controlada.

O desempenho resistente indicou, em média, que as estruturas romperam para cargas superiores a 235 vezes seu próprio peso, enquanto as estruturas de Stringari et al. (2020) romperam para cargas superiores a 97 vezes seu próprio peso. Esta diferença provavelmente está associada ao emprego do tirante na estrutura.

Conforme se previa em teoria, as estruturas apresentaram um aumento de rigidez com a utilização do tirante. As estruturas ensaiadas por Stringari et al. (2020) e Filippini (2020), que não utilizaram tirante, apresentaram na região da cumeeira deformações de $6,45 \mathrm{~mm}$ e $5,73 \mathrm{~mm}$, respectivamente, para o carregamento total de $6,95 \mathrm{kN}$, significativamente menor que o utilizado neste trabalho. Utilizando-se a equação de regressão apresentada na Figura 4 (a) e aplicando-se a carga de 6,95 kN obtém-se em média um deslocamento de 1,79 mm para as estruturas ensaiadas. Contudo, nas estruturas ensaiadas por Stringari et al. e Filippini o momento fletor na ligação rígida era da ordem de 1,37 kN.m enquanto que neste trabalho para a mesma carga tal momento fletor foi de $0,44 \mathrm{kN} . \mathrm{m}$

Neste trabalho, os pórticos só atingiram as flechas admissíveis para carregamentos totais da ordem de $30 \mathrm{kN}$, enquanto as estruturas de Stringari et al. (2020) e Filippini (2020), chegaram a este limite para carregamentos da ordem de 10 kN. Deste modo, fica evidente que o tirante contribui significativamente no aumento da rigidez da estrutura.

Os deslocamentos das estruturas até a carga de aproximadamente $12 \mathrm{kN}$ apresentaram comportamento semelhante. A partir de cargas mais elevadas, pode-se observar que os pórticos com maior densidade exibiram uma rigidez maior quando comparados aos pórticos de menor densidade. Isto pode ser observado na Figura 4. O mesmo comportamento foi constatado por Stringari et al. (2020) em suas estruturas.

Apesar de que o comportamento das estruturas quanto a resistência e rigidez possa ser considerado satisfatório, 
destaca-se que o ancoramento do tirante deve ser melhor estudado, preferencialmente com base na caracterização da madeira à compressão normal as fibras. Conforme se observa na Figura 3 (b), houve esmagamento da madeira provocado pela chapa de ancoragem do tirante. Embora não tenha sido caracterizado a madeira para compressão perpendicular às fibras, utilizou-se chapas metálicas com $40 \mathrm{~cm}^{2}$ de área, o que para critérios normativos seria o suficiente. Contudo, tal fenômeno pode ser evitado com a utilização de uma chapa de ancoragem de maior área.

\section{Conclusão}

As estruturas executadas apresentaram comportamento resistente satisfatório. Isto se justifica uma vez que romperam para uma carga média equivalente a 1,37 vezes a carga de verificação estabelecida.

$\mathrm{O}$ comportamento dos pórticos também foi satisfatório quanto à rigidez. Neste aspecto, destaca-se que, mesmo para elevados níveis de carga, os diagramas forças $\mathrm{x}$ deslocamentos foram aproximadamente lineares.

Obteve-se elevada correlação positiva entre a densidade aparente da madeira dos pórticos com suas resistências, evidenciando que a seleção prévia da madeira a ser utilizada acarreta um melhor desempenho da estrutura.

As evidências obtidas indicaram que o emprego de tirantes em pórticos laminados e colados promoveu a melhoria do desempenho mecânico quanto à resistência e rigidez.

Embora os resultados satisfatórios, acredita-se que a pesquisa possa gerar desdobramentos especialmente no sentido de melhorar o desempenho mecânico e/ou econômico de estruturas similares. O desempenho deste tipo de pórticos está associado ao comportamento de ligações coladas sob ação de elevados momentos fletores nas barras de madeira e, consequentemente, momentos de torção nos planos colados. Neste sentido, pesquisas associadas ao teste deste tipo de juntas, feitas multilaminadas, parece recomendável. Ainda, no sentido de aumentar a resistência sob forças gravitacionais, sugere-se que o estudo do uso de tirantes associado a reforços, similares à solução proposta por Filippini (2020), possa ser interessante. Outras contribuições ao estado da arte compreenderiam, por exemplo, a utilização de diferentes adesivos, a avaliação da variação de inércia dos pilares e estudos mais conclusivos sobre ligações tirante-madeira.

\section{Agradecimentos}

Aos funcionários dos laboratórios LEME e LATEM pela disponibilidade e valiosa ajuda no decorrer de todo o trabalho. À Coordenação de Aperfeiçoamento de Pessoal de Nível Superior - Brasil (CAPES), pela concessão da bolsa para a realização desta pesquisa.

\section{Referências}

American Society for Testing and Materials (2013) D 905: Standard test method for strength properties of adhesive bonds in shear by compression loading. Pennsylvania.

Arquinto J., Silva L. G. A., Esper F. J., Zacharias J. M. \& Filho M. M. O. (2019). Produção de bioplastico utilizando amido da semente de jaca (Artocarpus heterophyllus Lam). Anais do $15^{\circ}$ Congresso Brasileiro de Polímeros (15 CBPOL) - Bento Gonçalves, RS.

Associação Brasileira de Normas Técnicas (1997). NBR 7190: Projeto de estruturas em madeira.

Azevedo L. D., Geraldi M. S. \& Ghisi E. (2020). Avaliação do Ciclo de Vida de diferentes envoltórias para habitações de interesse social em Florianópolis. Ambiente Construído 20 (4): 123-141. doi.org/10.1590/s1678-86212020000400463

Bissoli-Dalvi M., Ferres S. C., Alvarez C. E. \& Fuica G. E. S. (2017). Avaliação da sustentabilidade da madeira por meio da ferramenta ISMAS. Floresta e Ambiente 24 (0): 1-7. doi.org/10.1590/2179-8087.077214

Canadian Wood Council. (2002). Wood-Frame Housing - A North American Marvel. Ottawa.

Couri Petrauski S. M. F., Silva J. C., Petrauski A. \& Della Lucia R. M. (2016). Analysis of Eucalyptus glued-laminated timber porticos structural performance. Revista Árvore: 40 (5): 931-939. doi.org/10.1590/0100-67622016000500017 
Research, Society and Development, v. 11, n. 2, e52711226109, 2022

(CC BY 4.0) | ISSN 2525-3409 | DOI: http://dx.doi.org/10.33448/rsd-v11i2.26109

Couri Petrauski, S. M. F. (1999) Desenvolvimento e teste de pórticos treliçados feitos de madeira de Eucalyptus citriodora e Eucalyptus grandis laminada e colada. Dissertação Mestrado. Universidade Federal de Viçosa.

Filippini D. F. (2020). Construção e ensaio de pórticos em madeira colada com reforço nas ligações. Dissertação Mestrado. Universidade Estadual do Oeste do Paraná.

Fundação Dom Cabral. (2013). Relatório de pesquisa: Como anda a gestão da sustentabilidade no setor da construção? https://www.fdc.org.br/conhecimento/publicacoes/relatorio-de-pesquisa-28065

Gandini J. M. D., Barata T. Q. F. \& Pablos J. M. (2017). Projeto de interfaces de componentes estruturais para sistemas construtivos pré-fabricados com emprego de madeira de florestas plantadas. Mix Sustentável: 3 (2): 83-90. doi.org/10.29183/2447-3073.MIX2017.v3.n2.83-90

Green M. \& Taggart J. (2017). Tall Wood Buildings: Design, Construction and Performance. Basileia: Birkhäuser.

Hafner A., Winter S. \& Takano A. (2013). Wooden products - Positive material in life - cycle analysis. Life - Cycle and Sustainability of Civil Infrastructure Systems. London: CRC Press.

Maiti R., Rodriguez H. G., Kumari C. A., Mandal D. \& Sarkar N.C. (2020). Sustainable Bioresource Management: Climate Change Mitigation and Natural Resource Convervation. $1^{\text {a }}$ ed. CRC Academic Press.

Marquardt L., Bender G. V., Wanderlind A. \& Vito M. (2018). Análise da resistência à flexão de vigas de madeira laminada colada com diferentes espessuras de lâminas. Revista Técnico-Científica de Engenharia Civil: 1(2): 42-56. dx.doi.org/10.18616/civiltec.v1i2.5085

Martens M. L., Kniess, C. T., Martens C. D. P. \& Monteiro Carvalho, M. (2016). Um estudo de inovação sustentável em projeto de desenvolvimento de produtos. Exacta: 14 (3): 477-494. doi.org/10.5585/exactaep.v14n3.6486

Petrauski A. (2000). Comportamento de ligações adesivas e avaliação experimental de tesouras de telhados feitas de laminado colado em madeira de Eucalyptus grandis. Tese Doutorado. Universidade Federal de Viçosa.

Petrauski A., Couri Petrauski S. M. F., Della Lucia R. M. \& Petrauski M. C. (2020). Methodology and device to obtain torsional shear strength of glued joints. Floresta: 50 (4): 1921-1930. dx.doi.org/10.5380/rf.v50i4.67140

Pfeil W. \& Pfeil M. (2003). Estruturas de madeira. (6a ed.), LTC.

Stringari E. H., Petrauski A., Couri Petrauski S. M. F., Azevedo R. L. \& Savaris G. (2020). Construction and testing of glued laminated timber frames for use in laying poultry houses. Engenharia Agrícola: 40 (2): 122-131. doi.org/10.1590/1809-4430-Eng.Agric.v40n2p122-131/2020

Tambosi S. S. V., Mondini V. E. D., Borges G. R. \& Hein N. (2014). Consciência ambiental, hábitos de consumo sustentável e intenção de compra de produtos ecológicos de alunos de uma IES de Santa Catarina. Revista Eletrônica de Administração e Turismo: 5 (3): 454-468. doi.org/10.15210/reat.v5i3.4761 